\title{
Optimalisasi Private Cloud Storage Berbasis Devstack Guna Meningkatkan Performansi Network Function Virtual
}

\section{The Optimization of Private Cloud Storage Based on Devstack to Improve The Performance of The Network Function Virtual}

\author{
Setiyo Budiyanto ${ }^{1}$, Kristiani N. Nahampun², Freddy A. Silaban ${ }^{3}$, Lukman M. Silalahi ${ }^{4}$, Fajar R. ${ }^{5}$ \\ ${ }^{1,2,3,4}$ Department of Electrical Engineering, Universitas Mercu Buana \\ Jl Meruya Selatan No.1, Kec Kembangan, Jakarta Barat, Indonesia \\ ${ }^{5}$ Department of Electrical Engineering, Universitas Pembangunan Nasional "Veteran" Jakarta \\ ${ }^{5}$ Jl. R.S Fatmawati No 1. Pondok Labu, Jakarta Selatan, Indonesia \\ sbudiyanto@mercubuana.ac.id ${ }^{1 *}$, kristianinatalia12@gmail.com ${ }^{2}$, freddy.artadima@mercubuana.ac.id ${ }^{3}$, \\ lukman.medriavin@mercubuana.ac.id ${ }^{4}$, fajarrahayu@upnvj.ac.id ${ }^{5}$
}

\begin{abstract}
Abstrak - Sistem NFV merupakan sebuah arsitektur jaringan yang menggunakan teknologi virtualisasi untuk seluruh fungsi platform jaringan dan fungsionalitas perangkat keras. Salah satu platform cloud computing yang dapat digunakan untuk membangun NFV adalah Devstack. Devstack merupakan sebuah tools untuk membangun layanan Private Cloud Storage. Melalui sistem ini, layanan Private Cloud Storage dapat berjalan didalam sebuah jaringan virtual. Pada penelitian ini dilakukan implementasi jaringan virtual menggunakan devstack yang berbasis insfrastruktur NFV pada layanan Private Cloud Storage, dilanjutkan dengan pengukuran QoS diantaranya adalah throughput, bit rate, jitter, dan delay. Melalui penelitian ini, dapat diketahui kemampuan suatu jaringan virtual pada suatu infrastruktur cloud computing. Berdasarkan standar ITU-T, nilai Jitter dan packet loss bernilai sangat baik.
\end{abstract}

Kata Kunci: Virtualisasi, Devstack, Network Function Virtualization, QoS, cloud storage.

\begin{abstract}
NFV system is a network architecture that used virtual technology for all network platform functions and hardware functionality. One of the cloud computing platforms that can be used to build NFV is Devstack. Devstack is a tool for building Private Cloud Storage services. Based on this system, the Private Cloud Storage service can load on a virtual network. This research, implemented the virtual networks using Devstack based on NFV infrastructure in the private cloud storage service, then the system measured the QoS including throughput, bit rate, jitter, and delay. The ability of a virtual network in a cloud computing infrastructure can be seen through this research. Based on ITU-T standard, jitter and packet loss value had a very good performance.
\end{abstract}

Keywords: Virtualization, Devstack, Network Function Virtual, QoS, cloud storage.

TELKA, Vol.6, No.1, Mei 2020, pp. 1 9

ISSN (e): 2540-9123

ISSN (p): 2502-1982 


\section{Pendahuluan}

Seiring perkembangan teknologi yang sangat cepat, sistem teknologi jaringan yang awalnya banyak menggunakan perangkat fisik cenderung berubah menjadi perangkat virtual. Sistem virtualisasi merupakan sebuah solusi yang berguna untuk kemajuan teknologi dimana dengan sistem virtulisasi ini sebuah perangkat keras jaringan seperti router, switch dan lainnya dapat dibuat menjadi perangkat virtual. Virtualisasi adalah proses membuat suatu hal menggunakan software untuk merepresentasikan sesuatu, seperti aplikasi, server, storage, dan jaringan virtual. Virtualisasi merupakan salah satu cara yang cukup efektif untuk mengurangi biaya IT namun bisa meningkatkan efisiensi dan fleksibilitas dalam melakukan pengembangan sistem jaringan pada suatu insfrastruktur $[1,2]$.

Pembangunan sebuah insfrastruktur jaringan diperlukan sebuah perangkat keras, dimana setiap perangkat keras memiliki fungsi yang terbatas, sehingga dalam membangun sebuah infrastruktur jaringan diperlukan banyak perangkat keras dan konfigurasi jaringan yang kompleks pada setiap perangkat keras. Hal ini menyebabkan tidak efektif dan tidak efisien dalam membangun insfrastruktur jaringan. Oleh sebab itu dengan adanya sistem virtualisasi diharapkan bisa membantu dalam pembangunan insfrastruktur jaringan dimana sebuah perangkat keras dapat memiliki fungsi yang luas dalam pembangunan insfrastruktur jaringan, yaitu Network Function Virtual (NFV) [3].

Dalam penelitian ini dilakukan implementasi jaringan virtual menggunakan devstack yang berbasis pada parameter kinerja yang diukur pada infrastruktur NFV pada layanan private cloud storage yang sudah diimplementasikan diantaranya adalah throughput, bitrate, jitter, dan delay. Hasil penelitian ini dapat diketahui kehandalan suatu jaringan virtual pada suatu infrastruktur cloud computing. Framework NFV adalah sebuah desain infrastruktur yang dikeluarkan oleh European Telecommunications Standards Institute (ETSI). Framework NFV ini digunakan untuk menstandarisasikan desain arsitektur dari NFV. Melalui framework tersebut diimplementasikan NFV, sehingga bisa dijadikan sebagai solusi rancangan sistem yang akan dibuat. Tujuan adanya framework tersebut pada dasarnya akan membuat fungsi-fungsi yang ada di NFV menjadi modular. Pada framework terdapat beberapa bagian atau layer diantaranya ada Network Function Virtualization Infrastruktur (NFVI), Virtualised Network Funtion (VNF), Element Management System (EMS), dan Operations and Bussiness Support System (OSS/BSS). VNF, EMS, dan OSS/BSS itu semua berjalan di layer NFVI. NFVI dapat dibagi menjadi dua infrastruktur, yang pertama adalah physical infrastructure yaitu komputasi perangkat keras, penyimpanan perangkat keras, dan jaringan perangkat keras. Kemudian yang kedua adalah infrastruktur perangkat lunak, infrastruktur ini berfungsi untuk menjalankan lapisan virtualisasi menggunakan teknologi yang disebut dengan hypervisor. Hypervisor berfungsi untuk menjalankan komputasi virtual (ESXi, KVM, QEMU), penyimpanan virtual (LVM, NFS), dan jaringan virtual (MPLS VPN, VRF).

\section{Metode Penelitian}

Penelitian yang dilakukan menggunakan pendekatan engineering. Arsitektur sistem mengacu pada platform Devstack. Berdasarkan pada arsitekturnya, rancangan penelitian yang dirancang dapat dilihat pada Gambar 1. 


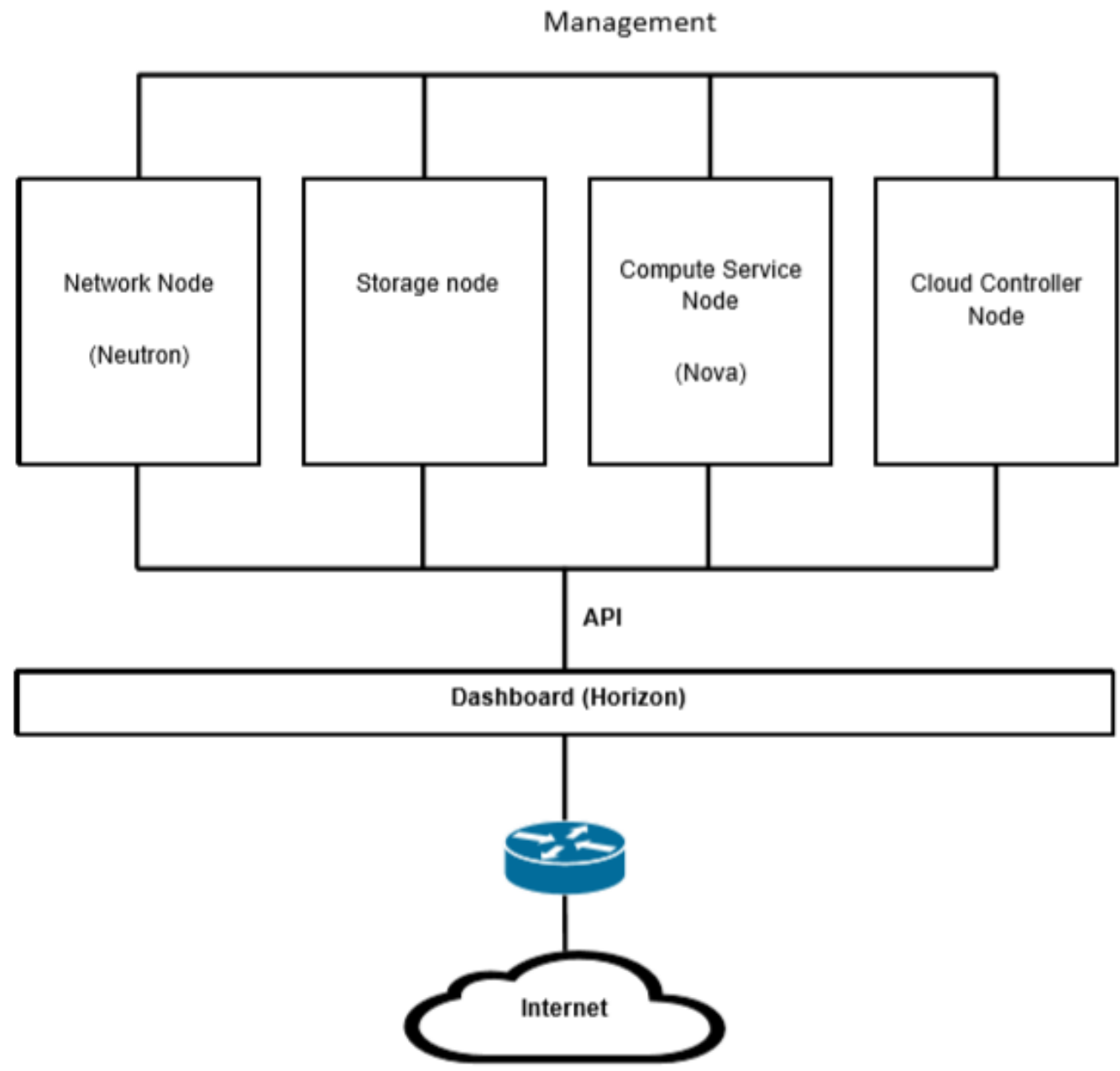

Gambar 1. Arsitektur Devstack.

Dengan mengacu pada skema di atas, sistem dikembangkan dengan Nextcloud, yaitu perangkat lunak cloud yang memberi kendali penuh atas data yang dimiliki. Nextcloud dirancang untuk individu dan organisasi dengan banyak pengguna. Secara fungsional hampir sama dengan dropbox yang banyak digunakan, dengan perbedaan nextcloud bersifat bebas (open-source) dengan demikian memungkinkan seseorang untuk memasang dan mengoprasikannya tanpa biaya pada server pribadi. Nextcloud adalah aplikasi yang dikelola secara aktif dari ownCloud. Nextcloud merupakan perangkat lunak opensource enterprise file sync dan share berbasis cloud [4]. Pengembangan sistem mengacu pada konsep komputasi cloud, termasuk penyimpan dan pemrosesannya. Cloud storage memiliki banyak keuntungan dibandingkan dengan penyimpanan data secara tradisional. Dalam penelitian ini digunakan sistem private cloud karena model ini cocok untuk perusahaan dengan skala enterprise yang sangat memperhatikan privasi dan keamanan data [5]. Cloud computing berbeda dengan grid computing atau paralel computing, dimana grid computing dan paralel computing adalah lebih merupakan sebuah bagian dari prasarana fisik bagi penyediaan konsep cloud computing. Server konvensional akan di batasi oleh jumlah core processor, harddisk dan memori [6], [7]. Sistem diuji dengan melakukan proses pengambilan data dari devstrack ke client. Selama proses ini akan diukur parameter QoS-nya. QOS merupakan suatu parameter uji kelayakan suatu layanan agar dapat dikatakan baik [6]. Beberapa parameter uji untuk QOS antara lain:

1. Delay

Delay merupakan waktu yang dibutuhkan oleh suatu paket data untuk menempuh jarak saat dikirim hingga sampai ke tujuan dan melewati antrian pengiriman yang padat [1]. Nilai 
parameter untuk delay dapat menggunakan rekomendasi ITU-T G 114 seperti yang ditunjukkan pada Tabel 1 [8], [9].

Tabel 1.Rekomendasi ITU-T G 114 untuk nilai delay.

\begin{tabular}{cc}
\hline Nilai Delay & Kualitas \\
\hline 0 & Sangat Baik \\
$1-150 \mathrm{~ms}$ & Baik \\
$151-400 \mathrm{~ms}$ & Cukup \\
$\geq 401 \mathrm{~ms}$ & Buruk \\
\hline
\end{tabular}

Nilai delay dihitung dengan persamaan

$$
\text { Rerata Delay }=\frac{\text { Total delay }}{\text { Paket yang diterima }} .
$$

2. Jitter

Jitter merupakan variasi delay yang terjadi karena adanya selisih waktu kedatangan paket pada jaringan IP [1]. Nilai jitter dihitung dengan persamaan

$$
\text { Jitter }=\frac{\text { Total variasi delay }}{\text { Pkt diterima-1 }} .
$$

Nilai parameter untuk jitter dapat menggunakan rekomendasi ITU T G 114, ditunjukkan pada Tabel 2 [1], [11].

Tabel 2. Rekomendasi ITU-T G 114 untuk nilai jitter.

\begin{tabular}{cc}
\hline Nilai Jitter & Kualitas \\
\hline 0 & Sangat Baik \\
$1-20 \mathrm{~ms}$ & Baik \\
$21-50 \mathrm{~ms}$ & Cukup \\
$\geq 51 \mathrm{~ms}$ & Buruk \\
\hline
\end{tabular}

3. Packet Loss

Packet loss merupakan parameter yang menunjukan besarnya nilai paket yang hilang akibat adanya penurunan sinyal pada jaringan, paket yang rusak serta kesalahan yang terjadi pada perangkat keras. Saat terjadi packet loss maka penerima akan meminta retransmisi sehingga dapat mengurangi nilai efisiensi pada jaringan [9], [10]. Parameter untuk nilai packet loss dapat menggunakan rekomendasi ITU-T G 114 seperti yang ditunjukkan pada Tabel 3 [10, 12]. Packet loss dihitung dengan persamaan

$$
\text { Packet Loss }=\frac{Y}{A} \times 100 \%
$$

dengan Y paket yang hilang, dan A adalah total paket yang dikirim.

Tabel 3.Rekomendasi ITU-T G 114 untuk nilai packet loss.

\begin{tabular}{cc}
\hline Nilai Packet Loss & Kualitas \\
\hline $0 \%$ & Sangat Baik \\
$1-3 \%$ & Baik \\
$4-15 \%$ & Cukup \\
$16-25 \%$ & Buruk \\
\hline
\end{tabular}

\section{Throughput}

Pengujian dilakukan dengan mengamati paket yang sukses terkirim ketujuan selama selang waktu tertentu. Kecepatan transfer data yang diukur dalam satuan bit per detik (bps). Throughput dapat dicari menggunakan persamaa [1]. Transfer data yang diukur dalam satuan bit per detik (bps). Setelah throughput didapatkan, maka dapat melihat nilai indeks dari throughput tersebut dalam Tabel 4. 
Tabel 4. Kategori penilaian throughput [10,12].

\begin{tabular}{cc}
\hline Throughput & Kategori \\
\hline $76-100$ & Sangat Baik \\
$51-75$ & Baik \\
$26-50$ & Cukup \\
$0-25$ & Buruk \\
\hline
\end{tabular}

Hasil dari pengujian kualitas jaringan akan dibandingkan dengan layanan platform Network Function Virtual AWS.

\section{Hasil dan Pembahasan}

Pengujian dan analisis hasil implementasi NFV menggunakan Devstack pada cloud storage yang telah dibuat ini bertujuan untuk mengetahui performansi kualitas jaringan NFV yang dibuat menggunakan Devstack pada layanan cloud storage. Hasil dari pengujian kualitas jaringan akan dibandingkan dengan layanan platform NFV lainnya seperti AWS yang berguna mengetahui platform NFV yang lebih baik berdasarkan parameter-parameter standarisasi ITU-T pada quality of service. Pengujian pada penelitian ini dilakukan dengan mengambil hasil yang didapat dari perangkat lunak Wireshark. Adapun skenario yang dilakukan pada pengujian ini dapat dilihat pada Tabel 5.

Tabel 5.Skenario pengujian.

\begin{tabular}{cc}
\hline Keterangan & Alat \\
\hline Alat Pengujian & Laptop \\
Jaringan ISP & Indihome \\
Software Monitoring & Wireshark \\
Software Server /OS & Nextcloud (Devstack dan AWS) \\
Software Client/OS & Google Chrome (Windows 10) \\
\hline
\end{tabular}

\subsection{Troughput}

Pengujian throughput mempunyai tujuan untuk mengetahui kecepatan (rate) transfer data efektif, yang diukur dalam bps dimana jumlah total kedatangan paket yang sukses yang diamati pada destination selama interval waktu tertentu dibagi oleh durasi interval waktu tersebut. Dilakukan pengujian sebanyak 3 kali sebagai berikut:

1. Pengujian ke-1

Pengujian ke-1 yang telah dilakukan dengan mengambil data dari Devstack ke client didapatkan selama 4 menit 35 detik.

2. Pengujian ke-2

Pengujian ke-2 yang telah dilakukan dengan mengambil data dari Devstack ke client didapatkan selama 4 menit 31 detik.

3. Pengujian ke-3

Pengujian ke-3 yang telah dilakukan dengan mengambil data dari Devstack ke client didapatkan selama 2 menit 10 detik.

Dari pengujian yang telah dilakukan, didapatkan nilai throughput pada pengujian ke-1 mendapatkan nilai sebesar $40.20 \%$ dan berdasarkan ITU-T termasuk kedalam kategori cukup, sedangkan pada pengujian ke-2 mendapatkan nilai throughput sebesar $42.60 \%$ yang berdasarkan pada ketentuan ITU-T termasuk kedalam kategori cukup dan pada pengujian ke-3 pada platform Devstack didapatkan nilai throughput sebesar $89,5 \%$ berdasarkan pada ketentuan ITU-T nilai tersebut termasuk kedalam karegori sangat baik, Hal ini menandakan nilai throughput pada platform Devstack pada pengujian ke-3 lebih baik dari pada pengujian ke-1 dan ke-2. Pada pengujian ke-3 nilai throughput pada cloud computing Devstack mampu melayani permintaan transfer rate dengan baik sehingga nilai throughput yang didapatkan termasuk dalam kategori sangat baik sedangkan pada pengujian ke-1 dan ke-2 termasuk kedalam kegori cukup, hal ini 
disebabkan pada saat proses pengiriman berlangsung tidak bisa melayani permintaan transfer rate dengan baik sehingga terjadi penumpukan paket data yang mempengaruhi nilai throughput.

\subsection{Delay}

Delay adalah waktu tunda yang diakibatkan oleh proses transmisi paket dari satu pengiriman ke tujuan. Delay diperoleh dari selisih waktu kirim antara satu paket TCP dengan paket lainnya. Mekanisme yang dilakukan pada pengujian parameter delay yang telah dilakukan sama seperti mekanisme yang dilakukan pada pengukuran throughput.

1. Pengujian ke-1

Pada pengujian ke-1 didapatkan nilai total delay sebesar 275.442 detik dengan total paket yang diterima sebesar 141554byte. Dengan menggunakan (1), diperoleh rata-rata delay pengujian ke-1

$$
\text { Rerata Delay }=\frac{\text { Total delay }}{\text { Paket diterima }}=\frac{275.442}{141554} \approx 1.95 \text { milidetik. }
$$

2. Pengujian ke-2

Pada pengujian ke-2 didapatkan nilai total delay sebesar 271.130 detik dengan total paket yan diterima sebesar 149101byte. Dengan menggunakan (1), diperoleh rata-rata delay pengujian ke-2

$$
\text { Rerata Delay }=\frac{\text { Total delay }}{\text { Paket diterima }}=\frac{271.130}{149101} \approx 1.81 \text { milidetik } .
$$

3. Pengujian ke-3

Pada pengujian ke-3 didapatkan nilai total delay sebesar 130.638 detik dengan total paket yang diterima sebesar 144238byte. Dengan menggunakan (1), diperoleh rata-rata delay pengujian ke-3

$$
\text { Rerata Delay }=\frac{\text { Total delay }}{\text { Paket diterima }}=\frac{129.47}{130506} \approx 0.99 \text { milidetik. }
$$

Dari pengujian yang telah dilakukan, didapatkan hasil nilai delay pada platform Devstack berbeda-beda dengan rata-rata delay terdapat pada pengujian ke-1 yaitu sebesar 1.95 milidetik dan hasil nilai delay terkecil adalah sebesar 0,99 milidetik diperoleh pada pengujian ke-3. Pada pengujian ke-1 hasil nilai delay sebesar 1.95 milidetik, berdasarkan ITU-T, termasuk kedalam kategori baik. Pada pengujian ke-2, didapatkan nilai sebesar 1.81 milidetik, dan berdasarkan pada kategori ITU-T, termasuk ke dalam kategori baik. Sedangkan pada pengujian ke-3, dengan nilai sebesar 0.99 milidetik, berdasarkan pada ketetapan ITU-T, termasuk kedalam kategori sangat baik. Dari pengujian menunjukan bahwa teknologi sistem jaringan pada platform Devstack mampu memberikan performansi yang baik dalam sebuah insfrastruktur jaringan komunikasi hal ini ditandai dengan kecilnya nilai delay pada pengujian ini.

\subsection{Jitter}

Pengujian jitter bertujuan untuk mengetahui kualitas kecepatan jaringan dengan mengumpulkan semua delay yang terjadi selama proses data dikirimkan sampai dengan data diterima. Mekanisme pengujian yang dilakukan yaitu dengan proses pengiriman data dari server ke client.

1. Pengujian ke-1

Dari pengujian ke-1 yang telah dilakukan dengan mengambil data dari devstack ke client didapatkan nilai total variasi delay sebesar 0,002326 detik dan paket yang diterima sebesar 141544 byte. Dengan menggunakan (2), diperoleh rata-rata nilai jitter pengujian ke-1 sebesar

$$
\text { Jitter }=\frac{\text { Total variasi delay }}{\text { Paket diterima }-1}=\frac{0,002326}{141544-1} \approx 0,0000164 \text { milidetik. }
$$


2. Pengujian ke-2

Dari pengujian ke-2 yang telah dilakukan dengan mengambil data dari devstack ke client didapatkan nilai total variasi delay sebesar $0,70553 \mathrm{~s}$ dan paket yang diterima sebesar 149101 byte. Dengan menggunakan (2), diperoleh rata-rata nilai jitter pengujian ke-2 sebesar

$$
\text { Jitter }=\frac{\text { Total variasi delay }}{\text { Paket diterima }-1}=\frac{0,70553}{149101-1} \approx 0,0047 \text { milidetik } .
$$

3. Pengujian ke-3

Dari pengujian ke-3 yang telah dilakukan dengan mengambil data dari devstack ke client didapatkan nilai total jitter sebesar 0,041607s dan paket yang diterima sebesar 144238 byte. Dengan menggunakan (2), diperoleh rata-rata nilai jitter pengujian ke-3 sebesar

$$
\text { Jitter }=\frac{\text { Total variasi delay }}{\text { Paket diterima }-1}=\frac{0,041607}{144238} \approx 0,00028 \text { milidetik. }
$$

Dari pengujian yang telah dilakukan didapatkan hasil dengan nilai rata-rata jitter pada pengujian ke-1 sebesar 0,0000164 milidetik, nilai rata-rata jitter pada pengujian ke-2 didapatkan nilai sebesar 0,004700 milidetik dan pengujian ke-3 sebesar 0,00028 milidetik. Jika mengacu terhadap nilai standarisasi pada ITU-T, nilai pada ketiga pengujian tersebut termasuk dalam kategori sangat baik sehingga sistem jaringan pada cloud computing mampu memberikan layanan kecepatan komunikasi dengan baik.

\subsection{Packet Loss}

Pada pengujian Packet loss dilakukan untuk mengatahui gagalnya paket data yang ditransmisikan kepada alamat tujuan sehingga menyebabkan hilangnya beberapa paket data pada saat proses pengiriman berjalan

1. Pengujian ke-1

Packet loss yang terjadi berlangsung sampai paket data selesai dikirimkan, dimana total packet yang terkirim pada platform Devstack sebesar 141544 byte dan paket data yang hilang sebesar 1101 byte. Menggunakan (3), nilai rata-rata pada parameter packet loss pengujian ke-1 adalah

$$
\text { Packet Loss }=\frac{\text { Paket hilang }}{\text { Total paket }} \times 100 \%=\frac{1101}{141544} \times 100 \%=0,77 \% .
$$

2. Pengujian 2

Packet loss yang terjadi berlangsung sampai paket data selesai dikirimkan, dimana total paket yang terkirim pada platform Devstack sebesar 149101 byte dan paket data yang hilang sebesar 2061 byte. Menggunakan (3), nilai rata-rata pada parameter packet loss pengujian ke-2 adalah

$$
\text { Packet Loss }=\frac{\text { Paket hilang }}{\text { Total paket }} \times 100 \%=\frac{2061}{149101} \times 100 \%=1,38 \% \text {. }
$$

3. Pengujian 3

Packet loss yang terjadi berlangsung sampai paket data selesai dikirimkan, dimana total paket yang terkirim pada platform devstack sebesar 144238 byte dan paket data yang hilang sebesar 1422 byte. Menggunakan (3), nilai rata-rata pada parameter packet loss pengujian ke-3 adalah

$$
\text { Packet Loss }=\frac{\text { Paket hilang }}{\text { Total paket }} \times 100 \%=\frac{1422}{144238} \times 100 \%=0,98 \% \text {. }
$$


Dari pengujian yang telah dilakukan terhadapa parameter packet loss didapatkan bahwa nilai packet loss pada pengujian ke-1 mendapatkan nilai sebesar $0,77 \%$ berdasarkan pada ITU-T nilai packet loss pada pengujian ke-1 termasuk kedalam kategori sangat baik. Pada pengujian ke-2 didapatkan nilai sebesar 1,38\%, sehingga berdasarkan ITU-T termasuk kedalam kategori baik. Nilai packet loss pada pengujian ke-3 sebesar 0,98\% dan berdasarkan pada ketetapan ITU-T termasuk kedalam kategori sangat baik. Dari data hasil pengujian tersebut nilai packet loss pada pengujian ke-1 dan ke-3 lebih baik dari pada pengujian ke-2 dengan nilai packet loss tertinggi sebesar $1,38 \%$.

\section{Kesimpulan}

Dari analisis yang dilakukan terhadap hasil pengujian layanan NFV pada Private Cloud Storage dapat disimpulkan bahwa Network Function Virtual berdasarkan pengujian yang telah dilakukan mampu memberikan kemampuan layanan jaringan dengan sangat baik, hal ini ditunjukan dari hasil pada parameter-parameter QOS yang telah dilakukan pengujian.

\section{Ucapan Terima Kasih}

Terima kasih kami ucapkan kepada semua pihak yang telah membantu menyelesaikan penelitian ini. Serta terima kasih kepada Universitas Mercu Buana atas dukungannya untuk publikasi penelitian ini.

\section{Referensi}

[1] Oktavianus, Y. L. "Membangun Sistem Cloud Computing dengan Implementasi Load Balancing dan Pengujian Algoritma Penjadwalan Linux Virtual Server pada FTP Server", Jurnal Nasional Teknik Elektro, vol. 2 No.1, p.25-30,2013.

[2] Ge, X., Liu, Y., Du, D. H., Zhang, L., Guan, H., Chen, J., \& Hu, X, "OpenANFV: Accelerating network function virtualization with a consolidated framework in openstack", ACM SIGCOMM Computer Communication Review, Vol. 44 No. 4)p. 353-354,2014.

[3] Nurohman, M., Hidayat, A. S., \& Riana, E, "Perancangan Private Cloud Computing Berbasis Nextcloud Pada Kementerian Perindustrian Jakarta", Jurnal Teknik Komputer, Vol 4 No.1,p. 48-55, 2018

[4] Santiko, I., Rosidi, R., \& Wibawa, S. A, "Private Cloud Storage As a Saving Media of Elearning Data on Educational Institutions".

[5] Sumarto, S., Thohari, A. H., \& Apriyani, M. E, "Rancang Bangun Lab Komputer Virtual Berbasis Cloud Computing Menggunakan Ovirt Pada Jaringan Terpusat", Jurnal Integrasi, Vol. 6 No.1,p. 72-76,2014

[6] Wati, A., Suroso, S., \& Sarjana, S, "Desain Penggunaan Qos (Quality Of Service) Pada Layanan Video Conference Point To Point Dan Multipoint Dengan Metode Kompresi Codec H. 264 Pada Jaringan 4G”, Prosiding SENIATI, Vol.4 No. 1, 37-42,2018

[7] Andi Adriansyah, Nanda Ferdana, Setiyo Budiyanto and Julpri Andika, "Design of Telemedicine Robot using Behavior-based Control Architecture with Two-Step Fuzzy Logic Optimization", Journal of Computer Science, Vol. 15, Issue 11, Pages 1617-1626, 2019.

[8] Recommendation, G, 114-One-way transmission time ITU, 2003

[9] Pratiwi, P. E., Isnawati, A. F., \& Hikmaturokhman, A, "Analisis QoS Pada Jaringan Multi Protocol Label Switching (MPLS) Studi Kasus di Pelabuhan Indonesia III Cabang Tanjung Intan Cilacap". Purwokerto: Akatel Sandhy Putra Purwokerto, 2013.

[10] Adilah, A, Virtualisasi Jaringan Dengan IP Multimedia Subsystem (IMS),2016

[11] Oki Teguh Karya, S S Saesaria and Setiyo Budiyanto, "RTP analysis for the video transmission process on WhatsApp and Skype against signal strength variations in 802.11 network environments", IOP Conference Series: Materials Science and Engineering, Vol. 453, No. 1,2018 
[12] Wulandari, A., Putri, A. R., \& Fadilah, R, Rancang Bangun Internet Protocol Television (IPTV) pada Jaringan Wireless LAN di Laboratorium Teknik Telekomunikasi "Protokol Signaling dan Performansi”, Prosiding Seminar Nasional Teknik Elektro Vol. 4, No. 3, pp. 393-403, 2019. 